\title{
Statistical Modeling for Hydrogen Production Using Wind Energy
}

\author{
Md. Shouquat Hossain, Adarsh Kumar Pandey, Mohsin Ali Tunio, Jeyraj A/L Selvaraj, Ali Wad Abbas \\ Al-Fatlawi, and Kazi Enamul Hoque
}

\begin{abstract}
This study contains a statistical model for hydrogen production through water electrolysis using wind energy. This is a modeling with experimental validation for the analysis of polynomial by planting ANOVA (Variables) method to Response Surface Methodology (RSM). The practical data for wind energy and electrical power are collected from the literature for this model. The wind turbine capacity has been taken to be $1 \mathrm{~kW}, 3 \mathrm{~kW}$ and $5 \mathrm{~kW}$ which is the low to high actual value and for output power low to high actual value has been taken as 0.7 to $6.2 \mathrm{~kW}$. The ANOVA method will be utilized to see other statistical proper tools as for actual and predicted values, response between residuals and predicted, 3-D surface and contour analysis plot. The statistical analysis shows that the planned model and the experiment results have a good fit.
\end{abstract}

Index Terms - Statistical model, wind energy, ANOVA method, hydrogen production.

\section{INTRODUCTION}

The use of renewable energy and its application in daily life is increasing day by day. The wind energy is one of the important renewable energy amongst others which are freely and abundantly available in the environment ready for use. The wind energy is being explored maximum around the world for e.g. Denmark, India etc. However, an efficient harnessing of wind energy is still a cause of concern. Therefore, researchers around the world are making their efforts to enhance the efficiency by hybridizing the wind energy with other renewable energies such as hydrogen energy. The hydrogen energy offers the opportunity to be used as a fuel to get a reliable power for almost every application that fossil fuel is being used [1].

The concept of hydrogen production by using three variables: time, wind turbine capacity and wind output power

Manuscript received January 29, 2015; revised July 29, 2015. This work was supported by University of Malaya, UMPEDAC, IPS, UMR and HIR/MOHE/ENG32.

Md. Shouquat Hossain and Adarsh Kumar Pandey are with the Centre of Research UMPEDAC, Level 4, Wisma R\&D, University of Malaya, 59990 Kuala Lumpur, Malaysia (e-mail: shouquat64@gmail.com, engi.shouquat@um.edu.my, adarsh@um.edu.my).

Mohsin Ali Tunio is with the Department of Electrical Engineering, Faculty of Engineering, University of Malaya, 50603 Kuala Lumpur, Malaysia (e-mail: mohsinalitunio@gmail.com).

Jeyraj A/L Selvaraj is with the Department of Educational Management, Planning and Policy, Faculty of Education, University of Malaya, 50603 Kuala Lumpur, Malaysia (e-mail: keh2009@um.edu.my).

Ali Wad Abbas Al-Fatlawi is with the Department of Mechanical Energy, University of Kufa, Najaf street, 00964 Najaf, Iraq (e-mail: aliwadi_77@yahoo.com).

Kazi Enamul Hoque is with Institution of Engineering and Technology, U.K. (e-mail: nasrudin@um.edu.my). will be utilized in this investigation. This statistical model will help to determine the necessary steps for the production of hydrogen energy using wind energy. This kind of model is related to the material engineering, which contains kinetics, physical property, mass and energy balance which is processing of a differential algebraic formula for both dynamic and steady state processes [2], [3]. The objective of this work is tantamount to investigate the production of hydrogen using wind energy through the statistical model. Also, to discover the optimum process parameters for hydrogen polymerization in a wind energy using RSM modeling and Central Composite Design (CCD) technique. This novel statistical model will contain all the basic model for producing hydrogen by using any wind turbine panel or hybrid system. So this study will help in predicting the result before doing the experiment also, the actual and predicted value of the results can be compared using the study.

\section{EXPERIMENTAL OVERVIEW}

This is a 2-D example model for wind energy used water electrolyzer system as showed in Fig. 1. The wind turbine capacity has been taken as $1 \mathrm{~kW}, 3 \mathrm{~kW}$ and $5 \mathrm{~kW}$ and the maximum hub height was taken as $20 \mathrm{~m}$. The yearly output power was collected from three different sites

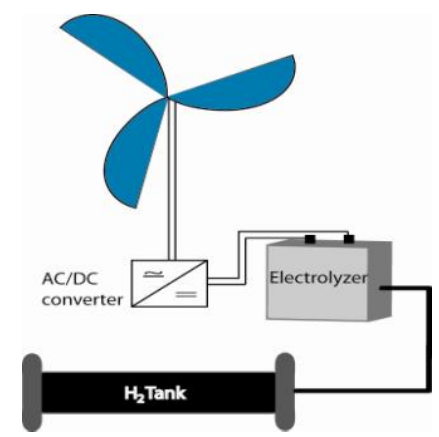

Fig. 1. 2-D basic diagram of wind turbine and electrolyzer system.

Novi Sad, Belgrade and Kopaonik and the average wind velocities of three sites were found to be between 3.16 to 4.76 $\mathrm{ms}^{-1}$ [4]. The alkaline electrolyzer HySTAT was chosen for this experiment having maximum hydrogen production rate of $1 \mathrm{Nm}^{3} /$ hour and hydrogen gas storage of 100 volumes. The wind turbine average winds velocities can be calculated using the below equation:

$$
\frac{U_{1}}{U_{2}}=\left(\frac{z_{1}}{z_{2}}\right)^{\alpha}
$$

where, $U_{1}$ and $U_{2}$ are wind velocities $\left(\mathrm{ms}^{-1}\right), z_{1}$ and $z_{2}$ are 
hights from ground $(\mathrm{m}), \alpha$ is a power-law exponent for the vertical wind profile having a value of 0.18 .

\section{DESIGN AND OPTIMIZATION}

In this study, the statistical model of wind power water electrolysis will appear results by using Stat-Ease software, where the CCD will help to analyze the interaction among the variables and to highlight the optimum process condition [5]. After calculation the experimental data of total wind power with the design procedures, an idealistic model has been completed according to the RSM methods [6]. In this time, the polynomial function has been adjusted with the statistical data at the initial stage and then the factor values will identify to optimize the real rmirical formula. The exactness of the polynomial model will be determined by the coefficient values $R^{2}$ and $R_{\text {adj }}^{2}$ in the equation form as given below [7]:

$$
R^{2}=1-\frac{\sum S_{\text {residual }}^{2}}{\sum S_{\text {model }}^{2}+\sum S_{\text {residual }}^{2}}
$$

$$
\frac{R_{\text {adj }}^{2}=1-}{\left(\sum S_{\text {residual }}^{2} / D_{g} F_{\text {residual }}\right.}
$$

Now the composite design of the system has been established by analyzing the response of the normal cubic meters of hydrogen conversion per mass mathematical equation will appear.

$$
\begin{aligned}
& Y_{\text {Response 1 }}=\beta_{\circ}+\sum_{i=1}^{k} \beta_{i} \chi_{i}+\sum_{i=1}^{k} \beta_{i i} \chi_{i}^{2} \\
& +\sum_{i=1}^{k-1} \sum_{j=i+1}^{k} \beta_{i j} \chi_{i} \chi_{j}+\varepsilon
\end{aligned}
$$

where $Y$ is the total response vector and taking model into the Linier, two-factor and Quadratic interaction effects and $\varepsilon$ is the error vector. The ideal preparation condition estimated the three-dimensional plot surface and regression analysis of the independent variables with each dependent variable. These independent variables are level controlled by $p$-value. At the same time signifies the interaction intensity between all independent variables interface for small $p$-value where point out the higher level of significance of the related variable. The second-order models has been tested by using ANOVA and the $F$-value method. The $F$-value can be formulated in the flowing way:

$$
F=\frac{M n^{2}{ }_{R G}}{M n^{2}{ }_{R D}}
$$

This model error will be represented by coefficients of variation $(\mathrm{CV})$ as given below:

$$
C V=\frac{S D}{\text { mean }} \times 100
$$

The $C V$ value should be not more than $10 \%$ for any model to be reproducible.

\section{RESULT AND DISCUSSION}

Use To assess the compatibility of the system, in this model three variables such as time $(A)$, wind turbine capacity $(B)$ and wind power output $(C)$ has been used. While, the main variables are wind turbine capacity and power output used for water electrolysis during the experiment. Table I shows, the units, type of the experiment (Numeric), low and high actual values and coded values: low (-1) high $(+1)$ for the three factors as discussed above.

The experiment runs about 20 numbers using CCD and the results are shown in Table II. The polynomial method

\begin{tabular}{|c|c|c|c|c|c|c|c|}
\hline Factor & Name & Units & $\begin{array}{l}\text { Type } \\
\end{array}$ & $\begin{array}{l}\text { Low } \\
\text { Actual } \\
\end{array}$ & $\begin{array}{l}\text { High } \\
\text { Actual } \\
\end{array}$ & $\begin{array}{l}\text { Low } \\
\text { Coded }\end{array}$ & $\begin{array}{l}\text { High } \\
\text { Coded }\end{array}$ \\
\hline $\mathrm{A}$ & time & hrs & Numeric & 1.00 & 365.00 & -1.000 & 1.000 \\
\hline B & $\begin{array}{l}\text { wind turbine } \\
\text { capacity }\end{array}$ & $\mathrm{kW}$ & Numeric & 1.00 & 5.00 & -1.000 & 1.000 \\
\hline $\mathrm{C}$ & $\begin{array}{l}\text { wind output } \\
\text { power }\end{array}$ & $\mathrm{kW}$ & Numeric & 700.00 & 6200.0 & -1.000 & 1.000 \\
\hline
\end{tabular}
equation has been used for plotting in three dimensional (3-D) and two dimensional (2-D) contours to identify individual factors, their intersection, reaction and response respectively. The mean square error $\left(\mathrm{Mn}^{2}{ }_{\mathrm{er}}\right)$ for this model is found to be 0.00007 which is very less and shows the model accuracy.

TABLE I: CODED LEVELS FOR EXPERIMENT DESIGN

The result of Response 1 showed that the hydrogen production ranged from 70 to $165 \mathrm{Nm}^{3}$. The maximum response of 165 has been found with the condition of $A$ is 8760 hours, $B$ is $5 \mathrm{~kW}$ and $C$ is $5200 \mathrm{~kW}$. It is very clear the experimental parameters for hydrogen electrolysis system can achieve optimum process condition.

The model fitting analysis by ANOVA method, where the $F$-value and $p$-value analysis has been utilized. The Sum of Squares final result model of Linear $(A, B, C)$, 2FI (2 Factor Interaction) $(A B, B C, A C)$ and Quadratic $\left(A^{2}, B^{2}, C^{2}\right)$ are $8460.48,558.56$ and 76.67 where the Mean Square results are
$2820.16,186.19$ and 25.59 . It is observed that the quadratic model is the best for this experimental design. The small $p$-values of $0.0001,0.0001$ and 0.0170 are less than the $F$-Values of 66.16, 19.65 and 5.51 (Prob $>F$ ) which indicates that the selected model can improve significantly. The proposed model quadratic equation is very important for identifying the independent variations tested to fit. The model accreted value at 0.9949 which is $99.49 \%$ valid and $0.41 \%$ overall cannot be pure. Another coefficient $R_{a d j}^{2}$ is 0.9904 , which shows a relation with the independent variables. The coefficient of variation $(C V)$ in this model is very low (1.95\%), 
which indicated a high performance and excellent model from the experimental results.

TABLE II: CCD EXPERIMENT RESULTS OF THE RESPONSE SURFACE

\begin{tabular}{lllll}
\hline \hline Run & Factor $\boldsymbol{A}$ & Factor $\boldsymbol{B}$ & Factor $\boldsymbol{C}$ & $\begin{array}{l}\text { Response 1 } \\
\text { Hydrogen } \\
\left(\mathbf{N m}^{\mathbf{3}}\right)\end{array}$ \\
\hline 1 & 4392 & 3.00 & 2050.00 & 106 \\
2 & 2952 & 3.00 & 2450.00 & 110 \\
3 & 4392 & 3.00 & 2850.00 & 112 \\
4 & 24 & 5.00 & 5100.00 & 160 \\
5 & 4392 & 3.00 & 2074.93 & 107 \\
6 & 4392 & 3.00 & 2210.00 & 113 \\
7 & 4392 & 3.00 & 2150.00 & 111 \\
8 & 8760 & 1.00 & 780.00 & 100 \\
9 & 4392 & 3.00 & 2650.00 & 114 \\
10 & 8760 & 5.00 & 5200.00 & 165 \\
11 & 24 & 1.00 & 767.00 & 99 \\
12 & 4536 & 3.00 & 2550.00 & 111 \\
13 & 4392 & 3.00 & 2420.00 & 108 \\
14 & 4392 & 3.00 & 1174.93 & 100 \\
15 & 4392 & 5.00 & 3450.00 & 130 \\
16 & 24 & 1.00 & 700.00 & 98 \\
17 & 4392 & 3.00 & 2950.00 & 115 \\
18 & 8760 & 1.00 & 700.00 & 97 \\
19 & 8760 & 5.00 & 700.00 & 70 \\
20 & 24 & 5.00 & 700.00 & 80 \\
\hline \hline
\end{tabular}

Now polynomial equation will be established with the help of multiple regression and squares method. This is a second order equation. From the study of the variation data, the response hydroden $(Y)$ can be formulated as:

$$
\begin{aligned}
& \text { Response Hydroden }(\%), Y=(1.57 \times A)+(21.16 \times B) \\
& +(20.37 \times C)-(2.49 \times A \times B)-(4.08 \times A \times C) \\
& -(32.99 \times B \times C)+\left(0.33 \times A^{2}\right)-\left(9.34 \times B^{2}\right) \\
& +\left(1.63 \times C^{2}\right)+118.47
\end{aligned}
$$

It is clear that $Y$ is the response of hydrogen production in $\mathrm{Nm}^{3}$ and $\mathrm{A}, \mathrm{B}, \mathrm{C}$ are independent coded variation.

\section{IDEOGRAPHIC FOR THE MODEL QUALITY}

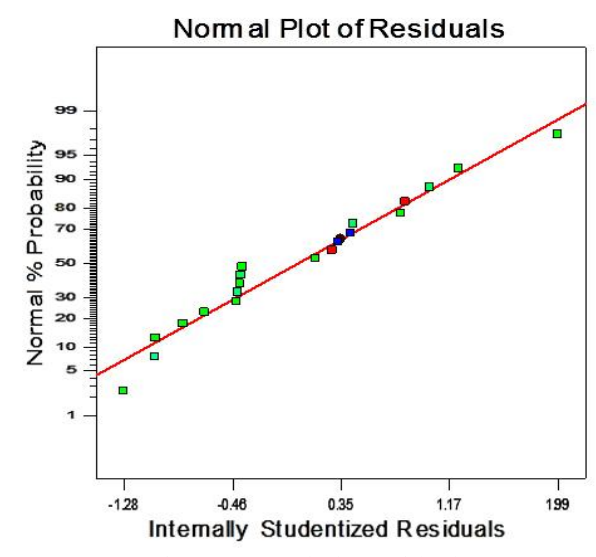

Fig. 2. Normal plot residuals.

The graphical represention of this model will see more identification of the experimental results. The results came out with the probability of residuals points, actual and predicted value on this statistic experimental model. The normal plot of residuals showed in Fig. 2, which is plotted with respect to the predicted values. However, this drift model has been used to calculate the prediction results of hydrogen production and compared with the experimental (Actual) consequences as shows in Fig. 3. This model will be more clearly the actual and prediction values and interaction between them. Fig. 4, represent the reaction between residuals vs. predicted data optimization for hydrogen response. From the Fig. 4, two side lines are standard maximum residuals range of \pm 3.00 . The values inside are totally related to the experimental response [8]. It is observed that the fitted model upon the response values created without unknown error. In the experimental time, the outliers are already tested because any time can occur to data arrange or may be severe error [9].

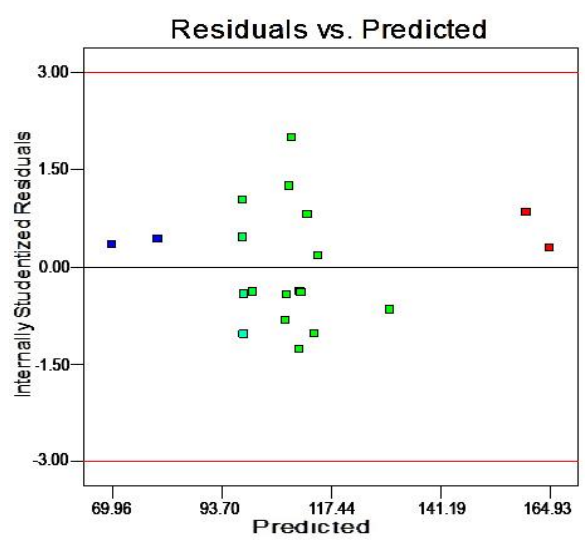

Fig. 3. Plotted prediction vs. actual.

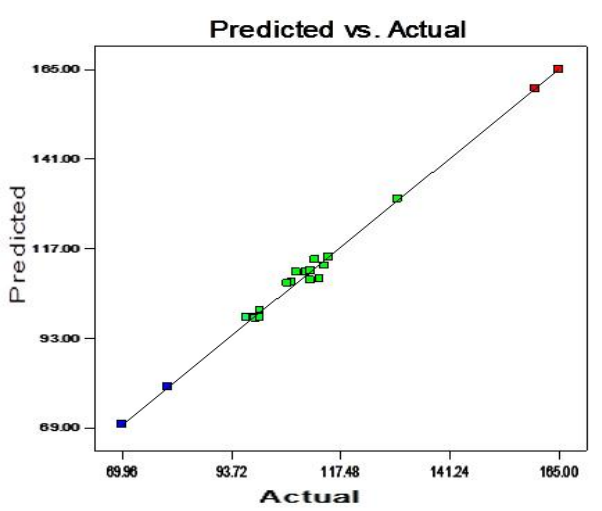

Fig. 4. Plotted residuals vs. predicted.

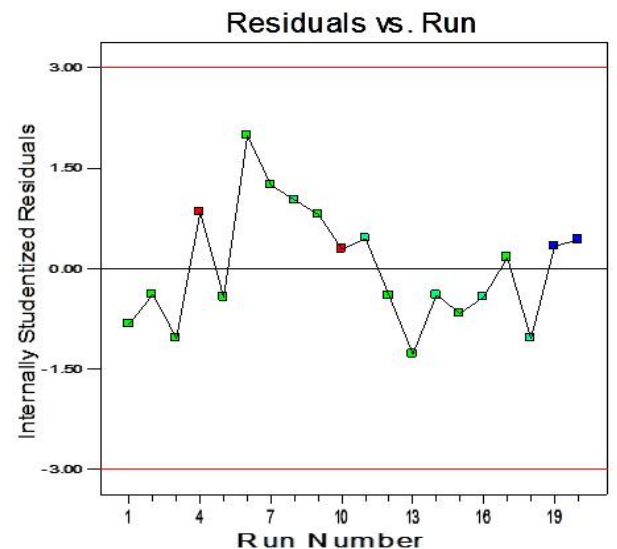

Fig. 5. Residuals vs. run.

Fig. 5 shows the residual vs run and the amount of hydrogen production run rate in $\mathrm{Nm}^{3}$ shows in Fig. 6. Fig. 6 is the hydrogen production rate with the help of three factors in perturbation plot. It is observed that the slope line is a factor, which is responsibile for the response (Hydrogen) and the flat line shows irresponsible for the response. From the Fig. 6, it is 
clear that the power factor $(\mathrm{B})$ is more effective for the output response.

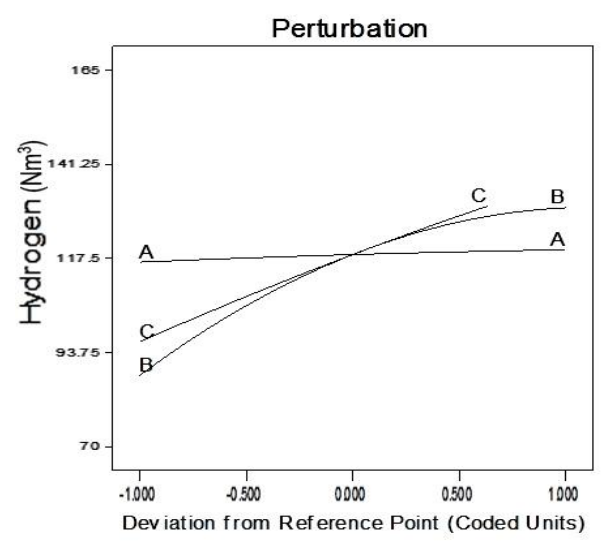

Fig. 6. Deviation plot for perturbation parameters.

\section{Model Response IN 3-D OUTLOOK ANALYSIS}

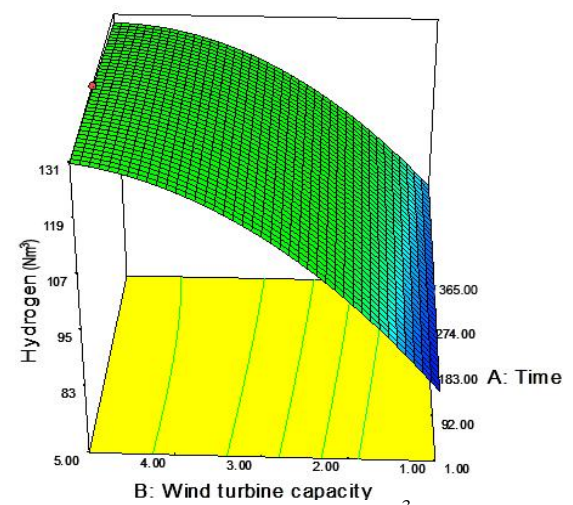

Fig. 7. 3-D plotted for hydrogen production $\left(\mathrm{Nm}^{3}\right)$. Wind turbine capacity vs. time.

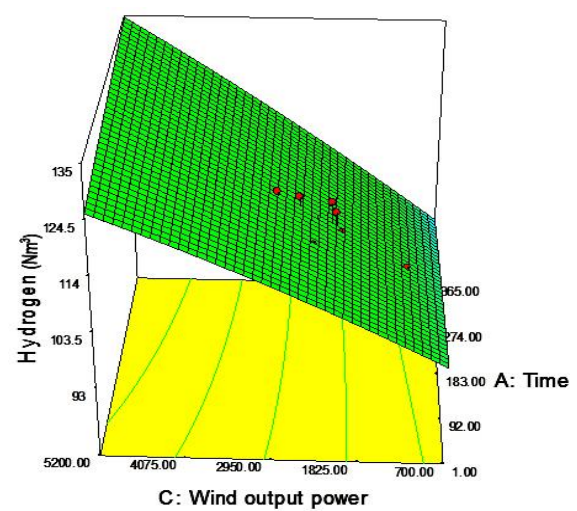

Fig. 8. 3-D plotted for hydrogen production $\left(\mathrm{Nm}^{3}\right)$. Wind output power vs. time.

The output result of this model has been involved in 3-D form. The 3-D plot of Fig. 7-Fig. 9, indicates the hydrogen production $\left(\mathrm{Nm}^{3}\right)$ with respect to wind turbine capacity $(B)$, power $(C)$ and time $(A)$. It is clear that at the starting point the production was low but when time, turbine capacity and power grows up, the level of the hydrogen production also increased. Fig. 7, shows the variation in time vs turbine capacity, where the hydrogen production rates are expected to be very slow due to the production independency on turbine capacity. Fig. 8, shows the variation in time vs wind power which also shows the inadequate production rates. Fig. 9, shows the variation in turbine capacity vs power which shows the effiective production rate of upto $164 \mathrm{Nm}^{3}$. The interaction level between three parameters has been explained by the response surface and further response will be constantly at their middle point.

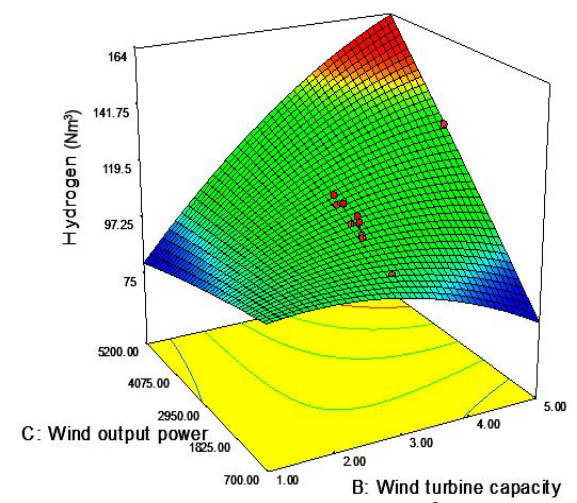

Fig. 9. 3-D plotted for hydrogen production $\left(\mathrm{Nm}^{3}\right)$. Wind output vs. wind turbine capacity.

\section{CONCLUSION}

The hydrogen production response by using a statistical model is a reliable method as described in the literature. The experimental results were compared with some prediction value and equations from this statistical model using the three different factors (independent variables) A, B and C. These independent variables were identified the most important parameters for hydrogen production. The maximum hydrogen response was considered to be $164 \mathrm{Nm}^{3}$, wind turbine capacity of $5 \mathrm{~kW}$, wind output power of $5200 \mathrm{~kW}$ and time of 8760 hours. The best part of this model was the comparison of the actual and prediction values which are a justification of a good model.

\section{ACKNOWLEDGMENT}

The authors are thankful to the UM Power Energy Dedicated Advanced Centre (UMPEDAC) and Professor Dr. Nasrudin Bin Abd Rahim. Institute of Research Management \& Monitoring (IPPP) and University of Malaya Research (UMR) and Institute of Graduate Studies (IPS), University of Malaya, Malaysia for funding this research work through the research grant (UM.C/HIR/MOHE/ENG/32).

\section{NOMENCLATURE}

$\Sigma S^{2}$ : sum of squares

$\Sigma S^{2}{ }_{\text {model }}$ : um of squares of model

$\Sigma S^{2}{ }_{\text {resideal }}$ : sum of squares of residual

$P$ : model parameters

$N$ : number of experiments

ANOVA: analysis of variance

CCD: central composite design

$M n_{R G}^{2}$ : mean of square regression

$M n^{2}{ }_{R D}$ : mean of square residual

$M n^{2}$ r: Mean square error

$S_{R G}$ : sum of squares

$S_{R D}$ : sum of residual

$D_{g} F_{\text {model }}$ : degree of freedom of model

$D_{g} F_{\text {residual }}$ : degree of freedom of residual

$R^{2}$ : determination coefficient 
$R^{2}{ }_{a d j}:$ adjusted coefficient of determination

$\mathrm{CV}$ : coefficients of variation

$F$-value: model significance

SD: standard deviation

$\mathrm{Nm}^{3} / \mathrm{h}$ : Normal Cubic Meters per hour

\section{REFERENCES}

[1] I. Dincer and T. A. H. Ratlamwala, "Development of novel renewable energy based hydrogen production systems: A comparative study," Energy Conversion and Management, vol. 72, pp. 77-87, August 2013.

[2] B. Glauß et al., "Spinnability and characteristics of polyvinylidene fluoride (PVDF)-based bicomponent fibers with a carbon nanotube (CNT) modified polypropylene core for piezoelectric applications," Materials, vol. 6, pp. 2642-2661, July 2013.

[3] J. F. Kennedy and C. J. Knill, Multicomponent Polymer Systems, U.K.: Longman Scientific \& Technical, 1992, p. 435.

[4] V. B. Vukman et al., "Technical analysis of photovoltaic/wind systems with hydrogen storage," Thermal Science, vol. 16, pp. 865-875, 2012.

[5] H. D. Setiabudi, A. A. Jalil, S. Triwahyono, N. H. N. Kamarudin, and R Jusoh, "Ir/Pt-HZSM5 for n-pentane isomerization: Effect of Si/Al ratio and reaction optimization by response surface methodology," Chem. Eng. J, vol. 217, pp. 300-309, February 2013.

[6] L. Sinopoli, M. Ordonez, and J. E. Quaicoe, "Wind turbine rotor modelling using response surface methodology," in Proc. 2010 23rd Canadian Conference on Electrical and Computer Engineering (CCECE), May 2010, pp. 1-5.

[7] M. J. H. Khan, M. A. Hussain, and I. M. Mujtaba, "Polypropylene production optimization in fluidized bed catalytic reactor (FBCR): Statistical modeling and pilot scale experimental validation," Materials, vol. 7, pp. 2440-2458, March 2014.

[8] D. T. K. Dora et al., "Hydrodynamics of three-phase fluidization of a homogeneous ternary mixture of regular particles-experimental and statistical analysis," Powder Technol., vol. 237, pp. 594-601, 2013.

[9] N. Aktaş, İ. H. Boyacı, M. Mutlu, and A. Tanyolaç, "Optimization of lactose utilization in deproteinated whey by kluyveromyces marxianus using response surface methodology (RSM)," Bioresour. Technol., vol 97, pp. 2252-2259, December 2006.

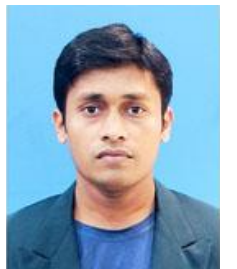

Md. Shouquat Hossain was born in Rajshahi, Bangladesh, on December 7, 1986. He got a bachelor of electrical and electronic engineering degree in 2009 from Ahsanullah University of Science and Technology, Bangladesh. He received his master of engineering science degree in the field of renewable energy in 2013 from the Faculty of Engineering, University of Malaya, Malaysia. He is now a PhD candidate ( $3^{\text {rd }}$ semester) at UMPEDAC, University of Malaya, Malaysia. His major field of study is renewable energy.

He becomes a research assistant in 2010 at the Faculty of Engineering, University of Malaya. He did publish and contribute several numbers of ISI journal and conference papers. His current job as a researcher at the same university of Malaya, Malaysia. His current research focus on the hybrid system (solar \& wind), renewable energy with building application, MPPT, solar PV efficiency, PVT, statistical model, micro-smart grid, solar PV efficiency, real time controlling and monitoring.

Mr. Hossain is a member of the Rotaract Club of Green Town (Rotary International District, 3280 Bangladesh). He is a member (student) of IEEE and IACT

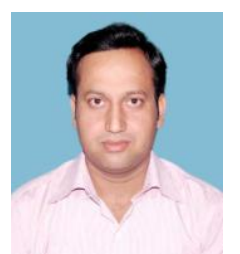

Adarsh Kumar Pandey was born at Purebichchhoor, Pratapgarh, India on April 5, 1983. He completed his schooling with the first class at various levels. He completed his bachelor of science degree from Ewing Christian College, Allahabad University, Allahabad, India in 2003. Then he completed his master of science degree from Purvanchal University and in 2005. Then he completed his post graduate diploma in rural energy technology from Mahatma Gandhi Institute of Rural Energy Planning and Development (MGIIREPD), New Delhi, in 2008. Finally, in November 2009 he joined as a full-time research scholar at the School of Energy Management, Shri Mata Vaishno Devi University, Katra, India for pursuing a doctoral degree in energy management and completed it in April 2013.

He joined the Solar Energy Centre, Ministry of New and Renewable Energy, Gurgaon, Haryana, India as a project fellow in May 2008 and worked there for 16 months. Then he started his Ph.D. program, during his Ph.D. research work, he had been awarded the National Renewable Energy Fellowship (NREF) from the Ministry of New and Renewable Energy, Government of India. Currently, he is working in UM Power Energy Dedicated Advanced Centre (UMPEDAC), University of Malaya, Malaysia as a post-doctoral fellow since August 2014 onwards. His area of research involves the design and (energy and exergy) analysis of different energy conversion systems including

Dr. Pandey is a member of Indian Science Congress Association, he has contributed several research papers in international journals of repute besides, he has presented few technical papers in the international conferences. He has also co-authored three book chapters besides, filed two Indian patents.

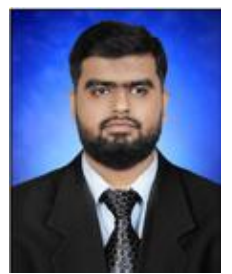

Mohsin Ali Tunio was born in Nawabshah, Sindh, Pakistan, on October 31, 1987. He received his B.Eng. degree in electrical engineering in 2009 from Quaid-e-Awam, University of Engineering, Science \& Technology, Pakistan and the M.Eng. degree in power system in 2012 from the University of Malaya, Malaysia.

Mr. Tunio has been a research assistant and Ph.D. candidate in the Department of Electrical Engineering, University of Malaya since 2012

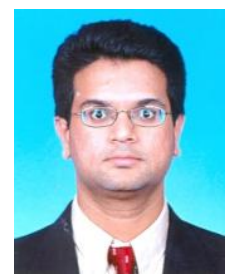

Jeyraj A/L Selvaraj was born in Kedah, Malaysia on April 9, 1980. He got his $\mathrm{PhD}$ degree in power electronics form University of Malaya, the MSc degree in electronics \& drivers, from University of Nottingham, Nottingham, U.K, and his B.Eng (Hons) degree in electronic, from University Multimedia Malaysia. His major focus on power engineering.

$\mathrm{He}$ is an editorial board member of International Journal of Energy and Power Engineering Research, Journal of Engineering Research and Technology, International Journal of Renewable Energy Resources. At present, he has been working as a senior lecturer in the Department of UMPEDAC, at the University of Malaya. He has published several numbers ISI, local journal and conference papers.

Dr. Selvaraj is a member of the IEEE and a member of BEM. He has been awarded form the Anugerah Perkhidmatan Cemerlang, University Malaya in 2013, Bronze Medal ITEX in 2010, MOSTI in 2010 Certificate of Appreciation, Sekolah Menengah Jenis Kebangsaan Chan Wa, Seremban in 2014 (National different professional bodies home and abroad of whom the member of the body of 'World Scholar' is worthy to mention.

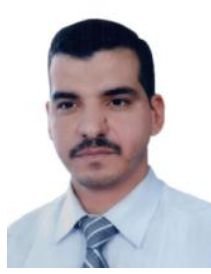

Ali Wad Abbas Al-Fatlawi was born in Najaf city in Iraq, 1977. He got his under graduate degree in 2001 from University of Kufa in Iraq in the field of mechanical energy. The University gives him a grant to complete his master degree in the university because of ranking during under graduate degree. He finishes his master study in 2004 in the field of energy then became a lecturer in the same university.

Ali received his Ph.D. degree in energy from University of Malaya at Kuala Lumpur in 2015. For more than 5 years, he was a lecturer in University of Kufa in Iraq. However, he works as an assistant researcher for two years in UM Power Energy Dedicated Advanced Centre in Kuala Lumpur, Malaysia.

Dr. Al-Fatlawi primary outside interest has been modelled and techno-economic analysis of renewable-energy systems. He also has a strong interest in artificial neural network and has published papers in ISI journals.

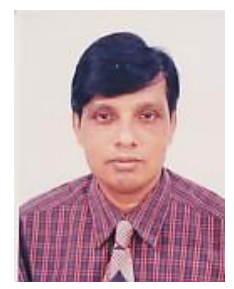

Kazi Enamul Hoque was born in Ratanpur, Brahmmanbaria, Bangladesh. Kazi had his PhD degree from University of Sains Malaysia, Malaysia in the year of 2008 with a major focus in education policy.

$\mathrm{He}$ has 20 years of experience of teaching at various educational organizations. At present, he has been working as a senior lecturer in the Department of Management, Planning and Policy at the University of

Malaya since 2009. He has published three books with renowned publishers and 40 full length research articles in peer reviewed journals. The area of his current research interest is to find how education policy can be supportive of energy policy to maximize the use of renewable energy in a country by creating mass awareness.

Dr. Kazi is a member of different professional bodies home and abroad of whom the member of the body of 'World Scholar' is worthy to mention. 